\section{Note on Radio-activity.}

IN the course of some experiments on the chemical behaviour of the $\beta$ and $\gamma$ rays from radium (Ramsay and Cooke, Nature, August II) solutions were obtained containing a radio-active substance which could sometimes be removed from the solution by the formation in it of a suitable precipitate. Sometimes when such a solution, containing ammonium saits, and in which several precipitations had already taken place, was evaporated to dryness on the lid of a porcelain crucible the residue was found to be capable of lessening the rate of leak of the electroscope, i.e. it behaved in the opposite way to an active residue, which would increase the rate of leak. This " anti-activity" has been observed on several occasions, and seems to be a specific property of the matter examined, and not to be due to any variable condition of the electroscope; thus the natural leak taken before is the same as that taken immediately after such an experiment.

I have not found any mention of a similar phenomenon in the literature on radio-activity, but should be glad to know if like results have been noticed by other observers. An explanation of the " anti-activity" would seem to be either that the leaf of the electroscope, which was always negatively charged, receives particles carrying a similar charge, which particles cause little ionisation of the air, or that the rays exert a de-ionising power on the air, if one can conceive of such an action. W. TERNENT COOKE.

Chemical Department, University College,

Gower Street, W.C.

\section{Blue Flints at Bournemouth.}

THERE is an old man living here, in Bournemouth, who years ago was employed in re-laying a part of the Poole Road, some little distance within the western boundary of the borough. He says that he helped to put down a quantity of refuse from the gas-works mixed up with flints, \&c.- - for this was before the days when the Poole Road began to be mended with granite. Now it so happened that this very man was employed to dig up and remove the surface of the road in preparation for the laying down of the tram lines, and of the wood pavement with which the whole road is now covered; and he says that he helped to dig up the very stuff which years ago he had helped to put down, and that this old road material was carted off to the new road then in course of construction upon the common and along the top of the cliff close by this part of the Poole Road. The flints, he says, came out blue, and are the blue flints now to be seen in patches upon this new road along the west sea-front.

Bournemouth.

\section{Intelligence of Animals.}

As some stray remarks of mine seem to have set this discussion agoing, I should be glad if you would kindly allow me to supplement your correspondents' interesting letters by two or three further stories which have come directly under my own observation. They are intended to be illustrative of methods of reasoning about reason in animals, particularly dogs. It will be observed that each story has its own distinctive shade of inaccuracy, and that the shade grows deeper as you proceed.

I trust, however, I shall by no means be taken as doubting the correctness of the facts sent you by your scientific readers, though I admit I might plead guilty to an indictment for suspecting seriously their interpretation. In the case of one or two of them I should not be surprised if some much more simple explanation than the one put forward might have been overlooked.

(I) Some years ago I had a favourite Irish terrier, Tim. Tim was a brave little chap, and would not quail before a lion. Like all of his strain, he had, I may say in passing, the rather human habit of grinning when amused, and would smile back at you in quite a comical fashion. This not too common trait is, I think, noteworthy.

When a mere puppy, Tim, in one bound, leaped into the household's good graces, and by no less meritorious an action than by saving us all from being burned alive. It was this way. Some newspapers thrown carelessly near the library grate caught fire; but Tim, who was snoozing on the hearthrug, bounded up and rushed to the cook, making such a row that that good lady dashed upstairs and tramped out the budding conflagration.

I am loth to point out that the young terrier could have had no more idea of a conflagration than Juno's geese when they cackled had of the Gallic invasion, from which by so doing they are said to have saved the Roman Capitol, and, further, I am greatly afraid that on the occasion showed not the foresight set down to his credit, but for once in his life-cowardice. The results, indeed, as not rarely happens from that species of wisdom, were satisfactory, and the appropriation of the praise on Tim's part quite after the manner of fully acknowledged rationals.

(2) In adult life Tim used to earn his breakfast of mornings by carrying my boots up to my room. Where his astuteness and "reasoning power" came in was by always fetching up polished boots, though he might have three or four pairs to pick and choose from. Of polished pairs he would invariably seize my light ones if they were at handa hint, the housekeeper used to insist, that he wished that I should "go off with myself " and visit friends.

When "doggie" stories are circling I seldom fail to extract this from my budget, and I am always tempted to add little flourishes. At all events, I never feel called upon to explain that Tim possessed no acquired taste for bog-mud and accordingly he discarded soiled shoes. Further, though Tim was by no means lazy, he set store by Helmholtz's great principle of the conservation of energy. He had experimented and discovered for himself that there was far less using up of brawn and muscle in bearing along and aloft a thin than a heavy, thick-soled boot. All this by no means appeared on the surface, and so his superlative judiciousness was a source of delight to the cook, and of bewilderment to her visitors, all the year round.

(3) A farmer residing near me has a strong, useful mongrel, Major by name. Though Major is a cur of low degree, his wisdom is great and " uncanny." Like every other dog around here he would almost know your thinking - to use the pet phrase--and certainly would understand your talking. The latter statement can be proved, and I beg to undertake the demonstration.

For agriculturists in these parts fairs are the grand monthly carnivals. Some months ago, on the eve of one, our farmer said to his wife as they sat by the fireside, "Jane, I think I must chain up Major to-night and not have him follow us to-morrow as he did on the last occasion." "Would you believe it," so the farmer relates it, " on hearing his sentence out marched Major, most indignant." Next morning at an early hour, as Jane and himself proceeded to the fair, there he was sitting on his tail on a fence looking out for them more than a mile from home! And so he was at the fun of the fair as well as another.

Our farmer never conjectured there might have been in the meantime for the mongrel an attraction of his own in the direction of the town, though the torn ear was there to set him thinking. Qui vult decipi, decipiatur.

(4) Another neighbour possesses a spotted dog which he calls a water spaniel. Though he, no less than every other puppy, whelp, and hound in the country, may be distinguished for intelligence, he and they are certainly not noted for good looks or long pedigrees. This particular thoroughbred, amongst many things, (a) can go on a message to any house he is directed to within a radius of three miles ! (b) can catch any hare he sets his eyes upon! and yet $(c)$ will be fifteen years old to a day if he lives until January 2 next !

Explanation :- His owner sometimes gives a loose rein to a splendidly vivid imagination.

I yield to no one both in my respect and liking for our canine friends and in my admiration for their affection, their highest developed quality. But I am inclined to think their good points and "thinking powers" are often vastly exaggerated by friendly and carelessly observing eyes. Much that surprises may be of the type of one or other of the four stories above given. Imperfect, ill-trained observation, reading into actions motives and purposes which were never dreamt of, setting aside the simple for the marvellous, assisted by a heavier or lighter dash of Munchausenism would turn folly into wisdom and wisdom into folly. By the help of any one of these principles one is quite capable of seeing in the most aimless action the profundity of the gods.

Creevelea, co. Leitrim.
Joseph MEEHAN. 